\title{
Perceiving mental states: Co-presence and constitution
}

\author{
Perceber os estados mentais: \\ copresença e constituição
}

Laura Danón ${ }^{1}$, Daniel Kalpokas ${ }^{2}$

\section{ABSTRACT}

Recently, several philosophers have called attention to the idea that there are occasions on which we can perceive (at least some) mental states of others. In this paper we consider two recent proposals in this direction: the co-presence thesis (Smith, 2010) and the hybrid model (Krueger and Overgaard, 2012). We will examine the aforementioned alternatives and present some objections to both of them. Then, we will propose a way of integrating both accounts which allows us to avoid such objections. Broadly stated, our idea is that by perceiving other people's behaviors we also perceive their mental states because behaviors co-present some features of the latter, and that this perception of others' minds is direct and immediate because behavior is a constitutive part of the mental states in question.

Keywords: mindreading, hybrid model, direct perception of other minds, co-presence thesis.

\section{RESUMO}

Nos últimos tempos, vários filósofos têm defendido a ideia de que, por vezes, podem-se perceber (pelo menos alguns) estados mentais dos outros. Neste artigo, vamos considerar duas propostas neste sentido: a tese da copresença (Smith, 2010) e o modelo híbrido (Krueger e Overgaard, 2012). Vamos examinar as alternativas mencionadas e apresentar algumas objeções contra eles. Então, vamos propor uma maneira de integrar ambas as explicações que nos permite evitar tais acusações. No geral, a nossa ideia é que, quando percebemos o comportamento dos outros nós também percebemos seus estados mentais, porque os estados mentais são coapresentados no comportamento, e que esta percepção das mentes dos outros é direta e imediata, porque o comportamento é parte integrante dos estados mentais em questão.

Palavras-chave: leitura mental, modelo híbrido, a percepção direta de outras mentes , tese de copresença.

\footnotetext{
${ }^{1}$ Universidad Nacional de Córdoba. Pabellón Agustín Tosco, Ciudad Universitaria, 5000, Córdoba, Argentina. E-mail: Idanon@gmail.com

${ }^{2}$ Universidad Nacional de Córdoba/CONICET. Pabellón Agustín Tosco, Ciudad Universitaria, 5000, Córdoba, Argentina. E-mail: dkalpokas@gmail.com
}

In ordinary life, we frequently talk about the mental lives of other people by using expressions such as "He looked very angry", "Don't you see that she is in pain?", "She sounded worried", etc. How should we understand those expressions? If we interpret them literally, it seems that they make reference both to certain mental states that are attributed to people and to a particular way 
of knowing about them: perception. But the mainstream tradition in philosophy of mind has understood this in a different way. In the debate about how we attribute mental states to others, the dominant positions usually only concede an indirect role to perception. It is generally accepted that perception only gives us knowledge about bodies and behaviors from which, after an additional extra-perceptual inferential process, we reach the mental states possessed by the person in question. However, in the last few years, a growing number of philosophers have defended the idea that, as those everyday claims seem to suggest, on some occasions it is possible to perceive the mental states of others (or at least some of them) in a direct way. ${ }^{3}$ The basic idea is that, in many of our encounters with other people, we have direct perceptual access to aspects of their mentality similar to the perceptual access to ordinary objects that we enjoy under normal conditions (Krueger and Overgaard, 2012; Krueger, 2012). ${ }^{4}$ In those cases, the contents of our perceptual states represent the mental states of other people; we literally see those mental states in their behavior. ${ }^{5}$ This thesis, according to which we can have direct perceptual access to the mental states of others, is frequently called Direct Social Perception (hereafter DSP). ${ }^{6}$

Now, according to some philosophers, it is important to distinguish different ways of understanding DSP (Krueger, 2012; McNeill, 2012; Herschbach, 2015; Michael and De Bruin, 2015; Bohl and Gangopadhyay, 2014): as a psychological, epistemological or phenomenological claim. In the first place, DSP can be an empirical, psychological claim about what sort of mechanisms enable us to attribute mental states to others (where it is frequently assumed that these mechanisms will be largely tacit or sub-personal). In this sense,
DSP aims to provide an alternative to traditional theories of mindreading like Theory-Theory (hereafter T'T) and Simulation-Theory (hereafter ST). While for the latter we only attribute mental states to others after non-perceptual processes involving theoretical knowledge or simulations, the former claims that it is possible to attribute mental states by using exclusively perceptual mechanisms.

Secondly, DSP could be mainly concerned with epistemological issues about how we can come to know the mental states of others, whether we can have perceptual and non-inferential knowledge of them, and what kind of evidence or justification (perceptual, inferential, etc.) we need to have in order to warrant those attributions. ${ }^{8}$ Under this reading, DSP opposes "inferentialism" (McNeill, 2012; Spaulding, 2015). According to inferentialists, all our knowledge about the mental states of others is inferential. We can have direct perceptual knowledge about the behaviors and gestures of other people, but we cannot have direct perceptual knowledge of their mental lives. Our knowledge about the mental states of others must be inferentially derived from our perception of their observable behavior and other non-mental features. DSP defenders, on the contrary, argue that when perceiving the behaviors of others we can directly perceive their mental states and, at the same time, obtain genuine non-inferential knowledge about them.

Finally, DSP could be understood as a phenomenological thesis regarding how other minds are consciously perceived. Those who defend DSP as a phenomenological claim reject a widely accepted assumption: that the minds of others are unobservable and that, as a consequence, all we can directly experience are their behaviors. Mentality must be somehow

\footnotetext{
${ }^{3}$ In the analytic tradition, some early advocates of this possibility are Wittgenstein (2009), McDowell (1998), and Dretske (1973). With some differences between them, recent defenders of this approach are Cassam (2007), Krueger and Overgaard (2012), Krueger (2012, 2013a, 2013b), Smith (2010), McGeer (2009), Gallagher (2008), Zahavi (2011), Stout (2010), and McNeill (2010).

${ }^{4}$ In the context of the epistemology of perception and philosophy of mind, the expressions "direct perception" and "immediate perception" are considered equivalent, and "direct" and "immediate" are mainly understood in the sense of "non-inferential". See, for instance, McDermid (2001), Malcom (1953), and Snowdon (1992). In particular, Snowdon (1992) elucidates the notion of direct perception as follows: a subject $\mathrm{S}$ directly perceives an object $\mathrm{O}$ if and only if $\mathrm{S}$ stands, in virtue of her perceptual experience, in such a relation to $\mathrm{O}$ that, if $\mathrm{S}$ could make demonstrative judgments, then it would be possible for $\mathrm{S}$ to make the true demonstrative judgment "That is $\mathrm{O}$ ". ${ }^{5}$ In this paper we will focus on the visual perception of mental states. However, we also consider it plausible to think that sometimes we can hear, feel, etc. the mental states of others. It would be possible, for example, that while talking to someone on the phone one could hear her sadness or feel someone's nervousness in her handshake.

${ }^{6}$ DSP advocates usually focus on intentions and perceptions as the kinds of mental states that can be directly perceived. It is more controversial whether DSP can be also extended to account for the attribution of other types of mental states with more indirect and tenuous links with behavior.

${ }^{7}$ See Herschbach (2008) and Lavelle (2012) for a defense of a sub-personal reading of the Simulation Theory (ST) and the Theory-Theory (TT). ${ }^{8}$ Sometimes philosophers disagree on whether DSP should be interpreted as an answer to the empirical question or to the epistemological one. For example, whereas McNeill (2012) focuses on DSP understood as an epistemological hypothesis, Krueger (2012) seems to be mainly interested in dealing with DSP as an answer to the empirical question (although Krueger, 2013a, also suggests that, once we endorse DSP and deny the unobservability of mental states, the epistemological problem of other minds dissipates). Thus, Krueger holds that the rivals of DSP are, in fact, the Theory-Theory and the Simulation Theory. Smith's position on the subject is more complex. On the one hand, he acknowledges that the epistemological side of the debate is the main concern in his paper. On the other hand, he presents DSP as an alternative to TT and ST, and he argues that, even though they are both usually proposed as descriptive/empirical theories, they can also be stated as answers to the epistemological debate on the inferential/non-inferential status of our knowledge of other minds. His main idea here is that, insofar as the input into the tacit theory/simulation process is the content of a perceptual state, TT and ST defenders will assume that such content does not yet ascribe mental predicates to others (Smith, 2010, footnote 4). Thus, according to them, some additional cognitive process must be added to perception in order to have knowledge of the minds of others.
} 
inferred from directly experienced public data. DSP advocates point out, instead, that we can have a direct experiential access to the minds of others; i.e., we can perceive their mental states in their gestures and behaviors (Bohl and Gangopadhyay, 2014).

These three ways of understanding DSP somehow reject that perceiving others' mental states involves inferential processes. But, as we shall see, the notion of inference changes in each of these debates. As mentioned above, when DSP is taken as a psychological claim, it opposes T'T and ST. Now, according to the interpretation usually given by DSP advocates, TT defenders claim that the inferences in question involve a body of theoretical knowledge about the causal/rational relations between mental states, environmental stimuli and behavior. ST advocates, instead, posit a process of simulation of the likely mental states of the others and a subsequent inference that allows the attribution of those simulated mental states to them (Herschbach, 2015) ${ }^{9}$. In any case, these inferential processes are generally considered to be sub-personal and tacit. They are not open to introspection, or conscious deliberation, nor do they have any phenomenologically distinctive character.

In the epistemic debates which revolve around how we can have knowledge of the mental states of others, the so called "inferentialists" consider that, in order to show how a subject $\mathrm{S}$ could count as knowing that another person $\mathrm{C}$ is in mental state $\mathrm{M}$, we need to posit an inference which allows the derivation of S's knowledge regarding C's mental states from a set of basic propositional perceptual states of $S$ - states about C's behavior, gestures and so on - and some generalizations which connect the latter with the former (McNeill, 2012). ${ }^{10}$ Hence, for the inferentialist, S's knowledge or awareness of C's mental states must always be inferentially derived from a more basic awareness of C's non-mental features. On the contrary, DSP defenders contend that we can sometimes have perceptual knowledge of the mental states of others, which is both epistemically basic and non-inferential.

Finally, when DSP is posited as a phenomenological or experiential claim, it opposes the idea that our experience of the mental states of others is always the experience of forming a belief about them via an inferential process from the conscious perception of their gestures and behavior (Herschbach, 2015). Thus, it rejects the idea that there is an actual inferential process, of which we are somehow aware, mediating between our perceptual states about the gestures and behaviors of others and our beliefs about their mental states. DSP defenders claim, instead, that, at least on some occasions, we directly experience the sadness or the anger in someone's face or in her behavior, instead of acquiring knowledge or beliefs about the sadness secondarily and as a result of perceiving such behavior.

These clarifications are important because, in recent times, many philosophers, neuroscientists, and psychologists have characterized perception itself as an inferential process (Hershbach, 2015; Michael and De Bruin, 2015). If this is so, all we can claim, at best, is that there is an indirect and inferentially mediated perception of the mental states of others, but never a direct one. ${ }^{11}$ Now, those who think that perception is inferential usually endorse a deflated, sub-personal, implicit and non-propositional notion of inference. That is why it seems to us that such a claim is only relevant, at best, for those interested in defending DSP as an empirical psychological claim.

Now, in this paper, we will focus on DSP as a personal-level hypothesis about both the epistemology and the phenomenology of perception, and we think that the claim that perception is inferential loses its relevance once we understand DSP in this sense. The reason is straightforward. In the epistemological debate, the kind of inferential process posed by the epistemic inferentialist, and rejected by DSP advocates, is one composed of propositionally structured premises (instead of being a non-propositional process). In turn, advocates of DSP as a phenomenological thesis reject that our access to the mental states of others is always experienced as indirect and inferentially mediated. Hence, they reject conscious, personal-level inferences as an ineludible component of our experience of other minds, not tacit sub-personal ones.

Now, when we try to clarify what DSP could consist of, the alternatives proliferate. In what follows, we will examine and evaluate two proposals: the co-presence thesis (Smith, 2010) and the constitution thesis - or the hybrid model(Krueger and Overgaard, 2012; Krueger, 2012). More specifically, we would like to examine the merits and limits of these two models, if we think of them as ways of fleshing out the epistemic and phenomenological versions of DSP. We do not aim to argue in favor of DSP against its inferentialist rivals. Instead, we would like to explore which would be the best theoretical alternative for those interested in adopting this approach. In the first section of the article, we present the co-presence thesis and an objection against it. In the second section, we briefly reconstruct the hybrid model of Krueger and Overgaard and, in turn, raise some challenges to it. In the third section, we present an alternative proposal that overcomes the criticisms presented against the two previous models and we show how the co-presence thesis and the constitution thesis can be successfully integrated. This third proposal intends to incorporate the best elements of the two others, providing us with a more adequate and stronger explanatory

\footnotetext{
${ }^{9}$ Herschbach (2008) provides reasons against such a reading of TT and ST.

${ }^{10}$ According to McNeill (2012), what the inferentialist claims is only that such an inference must be posited if we want to explain how a subject can count as having knowledge of the mental states of others, regardless of whether the subject in question does engage in any actual inferential process.

${ }^{11}$ The idea that we have an inferential perceptual access to the mental states of others is defended, for example, by Green (2010).
} 
model of what perceptual knowledge of the mental states of others could consist in.

\section{The Co-presence Thesis}

In his paper "Seeing Other People" (2010), Smith tries to shed light on the thesis that - at least on some occasions - it is possible to perceive other people's mental states. Smith does not deny that, sometimes, our knowledge of other minds is inferential or indirect. Nevertheless, he believes that this is not always so and, therefore, wants to clarify and defend what he calls "The Perceptual View". To do so, he combines a functionalist account of mental properties with a Husserlian thesis about perception.

Taking into account a well-known idea from Husserl, Smith points out that there is more to our visual experience than meets the eye. For example, when we visually perceive a solid object, like a cup, only a part of it faces us (i.e., only a part of it reflects light onto the retina to form the retinal image). Regardless of this, we experience the whole cup as a complete object with a front and a backside, and not merely as a bi-dimensional picture. Generalizing, physical objects are presented to us from a particular perspective, in virtue of certain modes of appearance that depend on our location in space with respect to them. Thus, in every perceptual experience of an object there is a core constituted by the aspects of it directly presented to sight. Yet, in each perceptual experience, this presented aspect is accompanied by other features of the object, which are not actually seen. These other aspects are co-presented when perceiving the object (they constitute, in Husserl's terms, "the internal horizon" of the perceived object). Thus, when we see a book, only one aspect of it is presented to us: its front. Even though they are not presented, its rear aspect and its innards are - according to Smithco-presented. When we perceive an object, its co-presented aspects are those that we anticipate would be presented to us if, for instance, we changed our location with respect to the object that we see. In fact, such anticipations have an "if... then..." structure because they refer to the features we would see if we moved or interacted with the perceived objects in certain ways. These anticipations are genuinely perceptual, rather than being mere beliefs about possible experiences. Nevertheless, Smith acknowledges that they lack the "intuitional fullness" of the fully presented aspects.

Basically, Smith's strategy consists of extending this notion of perception of physical objects to the perception of other people's mental states:

Just as the rear aspect of the book is visually present without being visually presented, so another's misery is visually present even though only their frown is visually presented. This view would count as a perceptual account of our access to others' mental states, but would also respect the deep-seated intuition that others' mental states are in some sense hidden from view (Smith, 2010, p. 739).

Briefly, the idea is that while behavior is presented in visual experience, mental states — strictly speaking - are only co-presented. ${ }^{12}$ Now, Smith adopts a functionalist conception of mental properties, according to which properties such as being angry or being in pain are functionally individuated in terms of the behaviors that their owners tend to carry out under certain circumstances. Thus, if $\mathrm{S}$ has a mental property $\mathrm{M}$, this means that $\mathrm{S}$ has a pattern of dispositions to behave in specific ways when $S$ is in circumstances $C$ or in the presence of certain stimuli I. Moreover, there is a set of conditional sentences of the form " $\mathrm{S}$ will behave in a certain way B in the presence of stimuli I" which describes such behavioral dispositions adequately. But then, let us suppose that by perceiving S's behavior we are able to precisely anticipate that $\mathrm{S}$ has those dispositions that individuate $\mathrm{M}$ (the mental property expressed by S's behavior). In such a case, we would be accurately grasping the functional role (or the dispositional profile) of M. And this would be -according to Smith- a way of perceiving that $S$ possesses the mental state $M$. In this way, Smith arrives at what he calls 'principle L'

(L) For any object $O$ and functional property $F$, if the perceptual anticipations in one's perception of $O$ 'latch onto' the functional role definitive of $F$, then one perceives $O$ as being F (Smith, 2010, p. 741).

According to Smith, (L) explains how the functional properties enter into the content of our perceptual experience. The "if... then..." structure, which reflects the perceptual anticipations we form when perceiving something, shows how perception can put us in contact with the functional properties characteristic of mental states.

Notwithstanding these virtues, the co-presence thesis has been objected by Krueger and Overgaard (2012) and Krueger (2012, 2013a). According to these authors, one problem with Smith's proposal is that the perception of others' mental states cannot be equated to the perception of a tridimensional object such as a tomato or a table because, in the latter case, we can move our head, our body, etc., until the occluded parts of the object become visually presented to us and not merely co-presented. However, nothing similar happens in the case of perceiving the mental states of others. Moving ourselves around, peering more closely or moving the body of the other person, will never bring their mental states into direct view. As Smith himself acknowl-

\footnotetext{
${ }^{12}$ Bohl and Gandgopadhyay (2013) and Gangopadhyay and Miyahara (2014) also suggest turning to Husserl's ideas in order to develop a better account of what perceiving another mind might consist in.
} 
edges, these can only be co-presented with the perceived behavior. Thus, they can never acquire the "intuitional fullness" of the fully presented.

Smith's answer to this objection is that our anticipations of co-presented mental states can be confirmed, not by means of subsequent presentations of those mental states as such, but rather by means of new behavioral presentations. What one anticipates, in the case of a co-presented mental state, are subsequent presentations of behaviors that, in turn, would co-present, if they actually took place, other mental states related to the first one. Thus, if your frown co-presents irritation, we can anticipate subsequent behaviors - such as cries - which would co-present related mental states, like anger. As Smith claims: "We can regard one's co-presentations of another's mentality to be fulfilled not, as with the rear aspect of the book, by the co-presented becoming presented, but by the co-presented and presented taking part in a harmonious experience" (Smith, 2010, p. 741).

A problem with this answer - Krueger and Overgaard argue - is that it leads us to conclude that the mental states of others "really are out of reach of our perceptual experiences. All we ever really see - have presented to us - is behavior. The mental, though somehow co-presented, is never really given as such" (Krueger and Overgaard, 2012, p. 245). Expressing it differently: mental phenomena remain unobservable in exactly the same way as the backside of the tomato (Krueger, 2012). In consequence, according to these authors, the Husserlian thesis of perceptual co-presence does not adequately explain the possibility of perceiving the mental states of others.

\section{The hybrid model and the constitutive relation: An objection}

After criticizing the co-presence thesis, Krueger and Overgaard delineate an alternative way of understanding DSP. Concisely, their proposal rests on a hybrid model, according to which some expressive behaviors are constitutive parts of mental phenomena.

Those who defend DSP typically claim that the minds of others are, at least on some occasions, perceptually accessible to us in their expressive behaviors. Nevertheless, Krueger and
Overgaard point out that this way of putting things remains ambiguous at a crucial point that needs further clarification. Basically, the problem is that it is possible to understand "expression", as the term is used when it is claimed that behavior expresses mental states, in at least three different ways.

A first alternative is to think that behavior expresses our inner mental states in the sense that the former is caused by the latter. But, as the authors argue, if we opt for understanding "expression" in this sense, we do not abandon the old Cartesian idea that mental states are essentially private, inner and experientially inaccessible to anyone but their owner. After all, for such a view, we can only directly perceive the behavioral effects of the mental states of others, but we can never perceive those mental states themselves. It is clear that such notion of "expression", which equates mental states to unobservable entities that can only be inferentially known, is not the one that defenders of DSP are in need of.

A second alternative is provided by the thesis of co-presence that we examined in the first section. In this case, claiming that certain behavior expresses certain mental states amounts to affirming that when we perceive the expressive behavior of another subject, associated mental phenomena are experientially co-presented. Nonetheless, as we have already mentioned, Krueger and Overgaard reject this second option because they believe that, since mental phenomena can only be co-presented but never directly presented to us in our perceptual experience, they end up being "phenomenally degraded" (Krueger and Overgaard, 2012, p. 244).

Finally, the authors hold that there is a more promising option, which consists of understanding "expression" in a constitutive sense. According to this third alternative, the behaviors of others express their mental states because they are proper parts or proper components of them. Mental states have a hybrid structure, composed of both internal processes (neural, psychological and/or phenomenal) and external, spatially located, and publically perceivable processes (bodily behaviors and gestures). The main idea here is that (at least some) mental states are complex wholes made up of different heterogeneous components with complementary functions. All these elements must come together and coordinate their respective functions harmoniously for the subject to have - or to experience - the mental state in question (at least in a full-blown sense) (Krueger, 2013a). ${ }^{13}$

\footnotetext{
${ }^{13}$ Does this mean that those behaviors which are proper parts of mental state $\mathrm{M}$ are also necessary to instantiate $\mathrm{M}$ ? The problem with such a strong claim is that, on many occasions, we attribute mental states to others even if they do not express them publicly. However, we think there is a better and more modest way of understanding the constitutive link between mental states and behavior (see also Newen et al., 2015, for a similar proposal). According to it, it is possible to have an instance of mental state $M$ even when one does not actually manifest any of the behaviors that are proper components of $\mathrm{M}$ and, conversely, it is also possible to perform those behaviors without having M. Nevertheless, there is a natural correlation between both of them, which allows us to say that paradigmatic or typical instances of $\mathrm{M}$ do involve those behaviors. The analogy with ordinary physical objects is clear. Imagine a book lacking its cover. That would not stop us from considering that this particular object is an instance of a book. Nevertheless, typical or paradigmatic instances of books have covers, and covers are indeed proper parts of books. Moreover, there seems to be a normative element involved here as well. Hence, when we see a coverless book, we feel justified in judging that something is missing in it. Likewise, imagine that someone who is supposed to be very sad does not show any of the usual manifestations of sadness. One may feel that something is missing here and, even more, one may look for excusing conditions that explain why those behaviors are absent.
} 
Since some of these constitutive elements are public and observable patterns of behavior, gestures and bodily actions, it is legitimate to conclude that, according to this view, our minds extend beyond our brains and reach out to the surface of our bodies and its behavioral responses (McNeill, 2012).

Krueger and Overgaard support this thesis by offering some empirical evidence in favor of the complementarity between the private and public components of mental states (see also Krueger, 2012, 2013a, 2013b). For example, people with Moebius Syndrome are incapable of facially expressing emotions, and this incapability seems to cause a decrease in the intensity of those emotions. Something similar is reported by patients who have received Botox injections, which inhibit the facial expression of emotions. These and other results suggest that neural and physiological processes must coordinate their functions with the relevant expressive-behavioral processes for the subject to be able to instantiate (full-blown) emotional experiences. According to Krueger and Overgaard, something similar is true in the case of intentions and thoughts. ${ }^{14}$ Thus, in all these cases, when we perceive certain expressive gestures and behaviors in the body of others, we literally perceive parts of their mental states. ${ }^{15}$

This third option, they argue, is the best one for those who wish to defend DSP, since it does not treat the mental states of others as Cartesian entities and does not imply either-as the co-presence thesis seems to do- that there is a phenomenological difference between the way in which we perceive behavior and the way in which we perceive mental states.

It is important to highlight the explicit anti-reductionism of the hybrid model defended by Krueger and Overgaard. As the authors themselves point out, if one wants to defend a constitutive link between behavior and mentality, one has two options:

(i) To claim that mental states are identical to, and nothing more than, the expressive behaviors that constitute them. This clearly implies a reduction of mental states to expressive behaviors.

(ii) To acknowledge that mental states are not equal to those behaviors with which they are, nevertheless, constitutively related. Gestures and behaviors are parts of mental states, but mental states also have other non-behavioral components (phenomenological, neurological, etc.).
Krueger and Overgaard clearly endorse (ii) and, consequently, they can easily avoid the risk of reductionist behaviorism. According to them, some mental states are hybrid in the sense that they are composed of inner and outer processes. The behavioral component of mental states remains distinct from, for example, the related neural activity or the phenomenological aspects of an emotional experience. Particular cases of cognition and emotion are instantiated by the complementary coordination of neural, physiological, and behavioral components.

At the same time, positing a constitutive link in this weak sense gives some initial plausibility to the claim that we can directly perceive (at least some of) the mental states of others. In order to see this point, let us focus on cases of ordinary perception of physical objects. In everyday life, we say, for example, that we see an iceberg even when only its tip emerges from the water. In such a case, we see an iceberg by seeing a proper part of it. Likewise, we say that we perceive a house even when, strictly speaking, we only see its front, etc. Analogously, Krueger and Overgaard argue, when we see certain expressive behaviors of other people, what we perceive, directly and without intermediaries, are the mental states of which they are proper parts.

Now, despite these virtues, the hybrid model faces its own problems. According to it, a subject can perceive the mental states of others directly, even though only parts of them - some of their expressive gestures and behaviorsare visually accessible to her. Now, imagine that a subject $\mathrm{S}$ is in front of another person $\mathrm{C}$, and $\mathrm{S}$ perceives certain gestures and behaviors of $C$ that, in fact, are proper parts of a mental state $\mathrm{M}$. Then two possibilities arise:

(a) On some occasions, $S$ will perceive C's mental state $\mathrm{M}$ in C's gestures and behavior. For example, when $\mathrm{S}$ is in front of $\mathrm{C}$ and $\mathrm{C}$ is frowning, she will perceive that $C$ is angry ( $S$ will see $C$ 's anger in C's behavior) and thereby she will obtain knowledge (or at least beliefs) about C's anger as such.

(b) On other occasions, instead, S will perceive C's behavior and gestures and, despite those behaviors and gestures actually being part of C's mental state $\mathrm{M}$, $S$ will fail to perceive $M$ in those behaviors. Thus, $S$ will neither have a conscious experience of $M$ nor acquire perceptually based knowledge or beliefs about Mas M. To give just one example, when $S$ sees $C$ frowning, she will be actually facing C's anger, but all $S$ will perceptually experience is the frown. $S$ will not see that $C$ is angry.

\footnotetext{
${ }^{14}$ The authors also present some evidence to support the claim that intentions are often embodied in expressive actions, something that makes them available to direct perception. For example, by the age of 7-9 months, infants seem to perceive certain ambiguous actions (like offering and withdrawing objects) as playful intention. Studies with human adults show, similarly, that viewers watching point-light displays of staged social actions were able to discern whether the activity was intended and not simply a chance encounter (see also Krueger, 2013a). Likewise, they quote several studies which support the suggestion that gestures may be part of cognitive processes like thinking and memorizing.

${ }^{15}$ The term "part" is used broadly and rather loosely in this context to include not merely particular physical objects and states, but also particular events and processes. See McNeill (2012).
} 
In other words, as seen above, even if some characteristic gestures and behaviors are proper parts of certain mental states, they are not identical to them. But then, even if people can sometimes perceive the latter in the former, they may not always do so. This seems to be what happens, for example, when a person unfamiliar with a specific context, or lacking enough experience, is only capable of seeing the movements of another person, describing them, etc., but is incapable of identifying which is the mental state that they express. A boy who sees an unknown girl smiling at him and tries to decipher the meaning of that gesture may be exactly in this situation. "Why is she smiling? Is she happy? Is she mocking me? Is she amused?" he may wonder. In such a case, despite clearly seeing that the girl is smiling, the boy fails to perceive the mental state that the smile expresses.

Something similar happens in some cases of perception of physical objects. To see this, let us return to the example of the subject $S$ who perceives an iceberg by seeing its tip. In such a case, $S$ only has direct visual access to the tip of the iceberg, but she does perceive the iceberg as an iceberg. Now, it seems that her accomplishment of such a feat involves some knowledge of the mass of ice under water or, at least, that it involves some expectations about its existence. Presumably, this is what allows $S$ to perceive the tip of the iceberg as an iceberg. But her twin, $S^{*}$, who lacks such knowledge/expectations, will be able to see the tip of the iceberg, but she will not perceive it as (a part of) an iceberg. $S^{*}$ will be deprived, then, of the possibility of perceiving the whole object.

Now, it is not clear how Krueger and Overgaard's proposal could allow us to differentiate the kind of situation described in (a) where S perceives C's mental state in her overt behavior from (b) where $S$ perceives C's behavior as mere behavior. In both situations we have a subject who perceives a proper part — some behavior - of a larger totality: the mental state. But why does it happen that sometimes the perceiver can have (some) epistemic perceptual access to the totality while, on other occasions, all she perceives is the proper part? Besides, how can we explain the difference between these two cases? Since Krueger and Overgaard are interested in elaborating DSP as a claim about the possibility of having perceptual experience and perceptual knowledge of the mental states of others, they need to elaborate an answer to these questions, but their account does not provide us with the necessary elements to do so.

In summary, Krueger and Overgaard owe us an explanation of how a subject who has visual access to some expressive behavior can have also a perceptual access to the mental state of which such behavior is a proper part. And, at this point, saying that some expressive behaviors are constitutive parts of mental states does not help at all, because a constitutive relation - as they characterize it - is just an ontological link that relates behaviors to mental states independently of any knowledge we may have of the aforementioned relata.

\section{Co-presence, constitution and partial knowledge of other minds}

In this section, we will try to show that Smith's proposal is a valuable tool if we want an account of DSP which allows us to distinguish perception of another person's mental states from perception of her current behavior. However, we still need to give an appropriate answer to Krueger and Overgaard's objection against the co-presence claim presented above, in the section devoted to presenting Smith's proposal. We will therefore argue, in what follows, that it is also possible to provide such an answer if one is willing to combine the co-presence thesis with the hybrid model defended by its critics. Thus, by articulating the co-presence thesis and the claim that there is a constitutive link between mental states and behaviors, we will both give a response to Krueger and Overgaard's objection against the former and provide an adequate explanation of what is required in order to perceive the mental states of others as such in their behaviors.

First, let us go back to Krueger and Overgaard's objection. The defender of co-presence argues that perceiving the mental states of others in their behavior is analogous to perceiving a tomato by seeing its front. In both cases, there is something that is visually presented to us (the behavior/the front side of the fruit) and hidden aspects that are merely anticipated or co-presented (the mental phenomena expressed in their behavior/the backside and the innards of the fruit). The problem is that the analogy fails at a crucial point. When we perceive three-dimensional opaque objects, we can move our bodies in different ways until what was merely co-presented becomes presented. The mentality of others, in contrast, can never be brought into a direct view in the same way. Of course, we can, as Smith claims, "confirm" that we have adequately perceived another person's mental state in her harmonious subsequent behavior. However, a central difference remains: while in the case of perceiving a tomato we can eventually come to see its backside directly, when we are facing an angry person, all we ever really see are simply different behavioral manifestations of her anger in different circumstances.

Thus, as Krueger and Overgaard argue, since all we ever directly see - all that is ever presented to us - are others' behavioral manifestations, we can doubt "whether CP [the co-presence thesis] makes any advance beyond more traditional accounts, according to which the mental states of others are 'unobservable' and thus must be inferred" (Krueger and Overgaard, 2012, p. 245).

How should we address this objection? A plausible reaction would be to reject Krueger and Overgaard's objection on the basis that it is unjustly oblivious to the fact that, according to Smith's account, co-presented aspects do constitute part of the content of perceptual experience. Thus, in what sense would it be fair to go on claiming that those mental states remain unobservable? 
Now, although this initial reply has some bite, we think that Krueger and Overgaard may still have a valid point. To see why this is so, imagine that we asked defenders of the co-presence model whether they think that those behaviors that are expressive of mental states are also proper parts of them or not. If these philosophers deny that expressive behaviors are proper parts of mental states, then they are committed to treating the latter and the former as "different existents". Now, according to Smith's model, our visual experience of others seems to be exhaustively composed of: (i) their presented actual behaviors; and (ii) the co-presented potential behaviors that are not being actually manifested but that, we anticipate, could be manifested under appropriate circumstances. Then, all we can experience perceptually - all that is ever presented or co-presented to us - are (actual or potential) gestures and behaviors. But if this is so, under the assumption that mental states might be something different from gestures and behaviors, it seems fair to conclude that Krueger and Overgaard are right to complain that, strictly speaking, we never have direct perceptual access to them.

Defenders of co-presence could avoid this perplexing conclusion, of course, by claiming that gestures and behaviors are proper parts of mental states. But this implies combining the co-presence thesis with the constitution thesis proposed by Krueger and Overgaard. Although Smith says nothing about it, it is worth noting that, in principle, there is no incompatibility between these two theses. Nothing in the co-presence thesis prevents us from thinking that the presented aspects of mental states of other people - their behavioral manifestations - could be constitutive parts of those mental states. In fact, claiming that gestures and behaviors can be proper parts of mental states allows us to keep a tighter analogy with the way in which, according to Husserlian philosophers, we perceive physical things. After all, when we perceive a tomato, the presented aspect -its front - and its co-presented aspects - its back and its innards - are all proper parts of the fruit. Likewise, one could consider manifest behaviors and gestures to be the presented proper parts of a larger whole: the mental state that they express.

What we would like to suggest, then, is that the weakness of the co-presence thesis resides not in how it explains what it means to have a perceptual experience, but in the ontological assumption that mental states are something entirely different from the gestures and bodily behaviors that express them. Thus, we believe that by integrating the hybrid model with the co-presence thesis we can obtain a better version of the latter, one that is more consistent with DSP than Smith's original proposal. But let us develop this idea a little more.

On the one hand, according to the hybrid model, gestures and behaviors express mental states because they are a constitutive part of them. On the other hand, the co-presence thesis claims that direct perceptual presentation of others' be- havior is accompanied by other aspects of their mental states which are anticipated by means of "if... then..." structures. By combining both theses, it can be claimed that the presented (and the co-presented) aspects of others' mental states are constitutively linked to the whole mental state. And it is precisely in virtue of that constitutive link that when perceiving an aspect of the mental life of another person (the behavioral aspect), we perceive a part of her mental state.

Even more, according to Smith's version of the co-presence thesis, whilst the gestures and behaviors of others can be visually presented to us, their mental states - their anger, their surprise, etc. - are merely co-presented. But now, in virtue of the suggested combination of the co-presence thesis with the constitutive thesis, we should substantially revise such a claim. When we are looking at someone's typical anger behavior, her anger is not merely co-presented to us. Rather, a part of her anger - the agent's behavior - is already presented to us, while another part remains co-presented. Thus, if we accept this combination of the co-presence thesis and the hybrid model, Krueger and Overgaard's original argument against Smith loses its force, as they can no longer claim that the mental state of another person is never presented to us in perception. The reason is straightforward: since expressive behaviors are proper parts of the mental states in question, when those behaviors are visually presented to us, the corresponding mental state is at least partially presented to us as well. Moreover, as has been repeatedly pointed out, what is co-presented to us when seeing an angry person's current gestures and behavior, what we anticipate, are other potential gestures and behaviors which, if they actually took place, would be proper parts of her mental state of anger. But, of course, if these potential behaviors actually occurred, they would become perceptually presented to us. Therefore, if this happened, the mental state constitutively linked to them would not be merely co-presented, but also (partially) presented in them.

To be clearer, our suggestion consists of combining a thesis about what perceiving the mental states of others consists in (the co-presence thesis) and an ontological thesis about the nature of those mental states of an agent that can be directly perceived by others (the hybrid model). Of course, the co-presence thesis, such as Smith elaborates it, presupposes an ontology of mental states that is quite different from the one that is held by Krueger and Overgaard. Smith seems to be committed to two different claims about the nature of mental states. On the one hand, he explicitly endorses a functionalist conception of mental states. On the other hand, he seems to accept the idea that mental states are internal and in some sense hidden from view (see Smith, 2010, p. 739). Now, it should be highlighted that even if many philosophers find it natural to combine their functionalist leanings with the claim that mental states are private, unobservable, and entirely constituted by internal properties, the former claim is, strictly speaking, independent of the latter. And it is only the claim about minds being internal and unobservable that should be 
abandoned in order to adopt the kind of hybrid view that we are presenting here. ${ }^{16}$

Our proposal concerning the compatibility of these two perspectives relies on the possibility of combining Smith's theory of how we can perceive the mental states of others and Krueger and Overgaard's thesis about the ontology of those perceived mental states. The co-presence thesis provides a promising model to understand what perceiving others' mental states can be, but fails to complement this with an appropriate conception of what mental states are. In contrast, the hybrid model provides a suitable conception of mental states (at least if one is interested in holding DSP), but fails to complement this with an adequate theory of perception. The solution to these shortcomings that we are offering here consists of retaining what we consider to be the best part of each model and dismissing the elements that, although present in them, constitute an impediment to elaborate a more coherent version of DSP.

Now, it may be argued that, even if the suggested integration of the co-presence and the constitutive theses were accomplished, mental states would still end up being "phenomenally degraded", since there may be some other aspects of another's anger - like its subjective dimension or the way it feels to be angry for that person - which would never become visually presented to us. However, the present proposal is prepared to explicitly acknowledge this point because the idea is not that we can perceive every aspect of the mental states of others. Something analogous happens, anyway, with the perception of ordinary objects. Just as we cannot perceive every aspect of a fruit that is ripe (we cannot perceive its atomic particles, for example), ${ }^{17}$ we are also not able to perceive the subjective dimension of others' mental states. Notwithstanding, it is still true that, if DSP is correct, we can perceive the mental states of others. Just as we can see that a fruit is ripe - although we cannot see every aspect of it - we can see that another person is angry -although we cannot see the subjective, or the neurophysiologic, dimension of her anger.
One last thing to note is that we are drawing the analogy between perceiving mental states and perceiving ordinary objects in a slightly different — and, to our mind, more accurate - way than the one Smith offers. To see this, let us return to the case of seeing a tomato. When we see a tomato, its front is presented to us while its back remains co-presented. Smith claims, analogously, that when we see that someone is angry, her behavior is the presented aspect, while the mental property - the anger itself- remains co-presented. But there are two additional points that can be made about the experience of seeing a tomato that Smith's analogy does not sufficiently take into account. First, what we experience is the tomato as a whole. Secondly, there are aspects or properties of the tomato (like its molecular properties) that are not perceived at all. Our proposal allows us to include these further aspects by saying that when we see someone's anger, we are presented with a part of it - certain behaviors - while other parts of it - a range of potential behaviors - remain co-presented. But, at the same time, what we are experiencing is the larger whole - the mental state of anger - of which the co-presented aspects are part. And of course, there are other aspects of this larger whole, such as its neurological or subjective properties, which are not part of our perceptual experience at all.

Let us turn now to the objection to Krueger and Overgaard's hybrid model that we presented above. According to it, to posit a constitutive relation between behaviors and mental states is not sufficient to explain how we are able to perceive those mental states as such merely by perceiving their behavioral manifestations. Now, this problem can also be solved by combining the hybrid model with the co-presence thesis. Consider the case of a person who frowns. What the defender of co-presence could now tell us is that in order to perceive that gesture as an expression of pain, it is necessary to take into account other aspects of that mental state, which, though not presented, are co-presented. We see the frown as a gesture

\footnotetext{
${ }^{16}$ Stricto sensu, functionalists are committed to the idea that what makes something a particular mental state is the way it functions, or the role it plays, in the larger system of which it is part (Levin, 2013; Wheeler, 2010). A traditional way of understanding the functionalist proposal may add to this that these mental states should be understood, metaphysically speaking, as internal entities that —at least in the case of human beings - are identical to or supervene on their owners' brains. In consonance, this kind of view will take the links between these internal mental states and external behavior to be merely causal. Now, this view can be contested. Thus, for example, the so called "liberal" or "extended" functionalist claim that mental states may extend beyond the body, coming to include different items in the creature's environment (Wheeler, 2010; Clark, 2008). The core functionalist idea that mental states have a constitutive, distinctive cognitive role or function is still part of this picture. But, now, the mental states that have this distinctive functional role can be realized in complex and heterogeneous material substrata - that may include internal states of the nervous systems, bodily states, processes and responses, and different entities in the external environment. Thus, mental states are better characterized as complex wholes constituted by these different components and their interactions. Analogously, it seems to us that it is possible to adopt a similar view, according to which at least some mental states extend beyond the brain, including the body and its behaviors (even though they may not include other items in the creature's environment). Advocates of such an embodied view should not understand mental states as purely internal (neural) items that interact in a merely causal way with gestures and behaviors. Rather, they might be thought as complex cognitive states composed of both certain internal states and some gestures and behaviors. And, even though, admittedly, theses different parts will interact causally in many ways - as many components of complex systems do-, these causal relations should be thought as relations amongst parts of these mental states. Consequently, both the causal relations between internal states and behavior and the relata in question will be constitutive components of these mental states. It seems to us that this kind of functionalism is perfectly compatible with the hybrid view that we are trying to defend here.

${ }^{17}$ At least we do not see them in the sense that is relevant to the present debate: that of being able to perceptually experience them as atomic particles.
} 
of pain because we can anticipate further behavior associated with it. That is what distinguishes perceiving the mental state of another person from merely perceiving her current behavior. In the first case, the perceiver locates the perceived behavior within a broader rational pattern of potential behaviors, and this is what allows her to perceive those behaviors as part of a larger whole: the mental state of the agent. ${ }^{18}$ If, on the contrary, a subject is capable of perceiving another agent's behavior but is incapable of making the appropriate anticipations of relevant future behavioral patterns of the agent, she will not be able to perceive that behavior as an expression (or as a part of) the agent's mental state. Thus, if we are willing to combine the co-presence thesis with the hybrid model, we will be in a position to solve the difficulties that, as we argued in the previous section, undermine the latter.

To sum up, we believe that the best alternative for the defender of DSP is to combine an ontological thesis, which posits a constitutive link between actual behavior and other aspects of the mental phenomenon, and an epistemic thesis - that of co-presence- which plausibly explains how perception directly provides knowledge of the mental states of others as such.

\section{Final remarks}

In this article we have tried to answer the question: which would be the best theoretical alternative for those interested in defending the thesis according to which we can directly perceive some mental states of other people? Taking into account two recent proposals - the co-presence and the constitution theses-, we have shown how their respective weaknesses can be overcome by combining both of them in a complementary way. The correct articulation of those proposals gives us, we think, a better way of understanding what direct perception of other minds could consist in.

\section{References}

BOHL, V.; GANGOPADHYAY, N. 2014. Theory of Mind and the Unobservability of Other Minds. Philosophical Explorations, 17(2):203-222.

https://doi.org/10.1080/13869795.2013.821515

CLARK, A. 2008. Pressing the Flesh: A Tension in the Study of the Embodied, Embedded Mind? Philosophy and Phenomenological Research, 76(1):37-59.

https://doi.org/10.1111/j.1933-1592.2007.00114.x

CASSAM, Q. 2007. The Possibility of Knowledge. Oxford, Clarendon Press, $244 \mathrm{p}$.

https://doi.org/10.1093/acprof:oso/9780199208319.001.0001

DRETSKE, F. 1973. Perception and Other Minds. Noûs, 7:3444. https://doi.org/10.2307/2216182
GALLAGHER, S. 2008. Inference or Interaction: Social Cognition without Precursors. Philosophical Explorations, 11(3):163174. https://doi.org/10.1080/13869790802239227

GANGOPADHYAY, N.; MIYAHARA, K. 2014. Perception and the Problem of Access to Other Minds. Philosophical Psychology, 28(5):695-714.

https://doi.org/10.1080/09515089.2014.895935

GREEN, M. 2010. Perceiving Emotions. Proceedings of the Aristotelian Society, Supplementary Volume, LXXXIV:45-61.

HERSCHBACH, M. 2015. Direct Social Perception and Dual Processes Theories of Mindreading. Consciousness and Cognition, 36:483-497

https://doi.org/10.1016/j.concog.2015.04.001

HERSCHBACH, M. 2008. Folk Psychological and Phenomenological Accounts of Social Perception. Philosophical Explorations, 11(3):223-235.

https://doi.org/10.1080/13869790802239268

KRUEGER, J.; OVERGAARD, S. 2012. Seeing Subjectivity: Defending a Perceptual Account of Other Minds. In: S. MIGUENS; G. PREYER (eds.), Consciousness and Subjectivity. Heusenstamm, Ontos Verlag, p. 239-262. https://doi.org/10.1515/9783110325843.297

KRUEGER, J. 2012. Seeing Mind in Action. Phenomenology and the Cognitive Sciences, 11(2):149-173. https://doi.org/10.1007/s11097-011-9226-y

KRUEGER, J. 2013a. Phenomenology and the Visibility of the Mental. Annual Review of the Phenomenological Association of Japan, 29:13-25.

KRUEGER, J. 2013b. Phenomenology of Person Perception. In: M. BRUHN; D. WEHRS (eds.), Neuroscience, Literature and History. New York, Routledge, p. 153-173.

LAVELLE, J. 2012. Theory-Theory and the Direct Perception of Mental States. Review of Philosophy and Psychology, 3(2): 213-2230.

https://doi.org/10.1007/s13164-012-0094-3

LEVIN, J. 2013. Functionalism. In: The Stanford Encyclopedia of Philosophy (Winter 2016 Edition). Ed. by Edward N. Zalta Available at: https://plato.stanford.edu/archives/win2016/ entries/functionalism/. Accessed on: 07/03/2013.

MALCOLM, N. 1953. Direct Perception. Philosophical Quarterly, 3:310-316. https://doi.org/10.2307/2217098

McDERMID, D. 2001. What is Direct Perceptual Knowledge? A Fivefold Confusion. Grazer Philosophische Studien, 62(1):1-16.

McDOWELL, J. 1998. Criteria, Defeasibility, and Knowledge. In: J. McDOWELL, Meaning, Knowledge, \& Reality. Cambridge, Harvard University Press, p. 369-394.

McGEER, V. 2009. The Skill of Perceiving Persons. The Modern Schoolman, 86(2/3):289-318. https://doi.org/10.5840/schoolman2009863/45

McNEILL, E.S. 2010. On Seeing that Someone Is Angry. European Journal of Philosophy, 20(4):575-597. https://doi.org/10.1111/j.1468-0378.2010.00421.x

McNEILL, E.S. 2012. Embodiment and the Perceptual Hypothesis. The Philosophical Quarterly, 62(248):569-591. https://doi.org/10.1111/j.1467-9213.2012.00065.x

\footnotetext{
${ }^{18}$ Once again, we are not claiming that we should reduce mental states to behavioral patterns. We are only committed to the epistemic claim that being capable of anticipating certain rational patterns of behavior is what allows us to perceptually identify some mental states of others as such.
} 
MICHAEL, J.; DE BRUIN, M. 2015. How Direct is Social Perception? Consciousness and Cognition, 36:373-375. https://doi.org/10.1016/j.concog.2015.08.005

NEWEN, A.; WELPINGHUS, A.; JUCKEL, G. 2015. Emotion Recognition: The Relevance of Perception. Mind and Language, 30(2):187-208. https://doi.org/10.1111/mila.12077

SMITH, J. 2010. Seeing Other People. Philosophy and Phenomenological Research, 81(3):731-748. https://doi.org/10.1111/j.1933-1592.2010.00392.x

SNOWDON, P. 1992. How to Interpret 'Direct Perception'. In: T. CRANE (ed.), The Contents of Experience. Cambridge, Cambridge University Press, p. 48-78. https://doi.org/10.1017/CBO9780511554582.004

SPAULDING, S. 2015. On Direct Social Perception. Consciousness and Cognition, 36:472-482.

https://doi.org/10.1016/j.concog.2015.01.003
STOUT, R. 2010. Seeing the Anger in Someone's Face. Proceedings of the Aristotelian Society, Supplementary Volume, 84:29-43. https://doi.org/10.1111/j.1467-8349.2010.00184.x

WHEELER, M. 2010. In Defense of Extended Functionalism. In: R. MENARY (ed.), The Extended Mind. Cambridge, MIT Press, p. 245-270.

https://doi.org/10.7551/mitpress/9780262014038.003.0011

WITTGENSTEIN, L. 2009. Philosophical Investigations. Singapore, Wiley-Blackwell, $321 \mathrm{p}$.

ZAHAVI, D. 2011. Empathy and Direct Social Perception. Review of Philosophy and Psychology, 2/3:541-558. https://doi.org/10.1007/s13164-011-0070-3

Submitted on July 06, 2017 Accepted on August 14, 2017 